\begin{tabular}{|c|c|c|}
\hline \multirow{3}{*}{$\begin{array}{r}\text { Case Reports in } \\
\text { Gastroenterology }\end{array}$} & \multicolumn{2}{|c|}{ Case Rep Gastroenterol 2017;11:190-200 } \\
\hline & $\begin{array}{l}\text { DOI: 10.1159/000468514 } \\
\text { Publisned onlıne: April I0, } 2017\end{array}$ & $\begin{array}{l}\text { (C) } 2017 \text { The Author(s) } \\
\text { Published by S. Karger AG, Basel } \\
\text { www.karger.com/crg }\end{array}$ \\
\hline & $\begin{array}{l}\text { This article is licensed under } \\
\text { International License (CC BY-N } \\
\text { Usage and distribution for comm }\end{array}$ & $\begin{array}{l}\text { nons Attribution-NonCommercial } 4.0 \\
\text { ger.com/Services/OpenAccessLicense). } \\
\text { uires written permission. }\end{array}$ \\
\hline
\end{tabular}

\title{
Utility of Glissonean Pedicle Transection for Surgical Treatment of Severe Liver Trauma
}

\author{
Satoshi Koizumi ${ }^{\mathrm{a}} \quad$ Kenta Katsumata $^{\mathrm{a}}$ Tatsunori Ono $^{\mathrm{a}} \quad$ Kouhei Segami $^{\mathrm{a}}$ \\ Hiroyuki Hoshino $^{a} \quad$ Masafumi Katayama $^{a}$ Shinjiro Kobayashi ${ }^{a}$ \\ Junichi Matsumoto $^{b}$ Shigeki Fujitani $^{\text {b }}$ Yasuhiko Taira $^{\mathrm{b}}$ \\ Takehito Otsubo ${ }^{a}$ \\ ${ }^{a}$ Division of Gastroenterological and General Surgery, St. Marianna University School of \\ Medicine, Miyamae-ku, Japan; ${ }^{b}$ Department of Emergency and Critical Care Medicine, \\ St. Marianna University School of Medicine, Miyamae-ku, Japan
}

\section{Keywords}

Glissonean pedicle ligation · Damage control surgery · Liver trauma

\begin{abstract}
The most common initial strategy for treatment of severe liver trauma is damage control in which hemostasis is achieved by perihepatic gauze packing and/or vascular embolization. However, we encounter patients in whom this strategy alone is not adequate. We have applied the principles of Glissonean pedicle transection, a technique that was originally devised to ensure safe and quick performance of planned hepatectomy for liver cancer, to 3 cases of severe liver trauma. We performed Glissonean pedicle ligation during damage control surgery in 2 patients and Glissonean pedicle transection during the definitive surgery in 1 patient. We describe the approaches and our experience with them, including operation times and outcomes. From our experience thus far, it seems that $8-12 \mathrm{~h}$ after the damage control procedure is appropriate for performing the definitive surgery. Although there are some problems posed by this strategy and cases to which it will not be applicable, the method seems to be particularly useful for cases of severe liver trauma in which the damage is exten-
\end{abstract}




\section{Case Reports in Gastroenterology}

Case Rep Gastroenterol 2017;11:190-200 DOI: $10.1159 / 000468514$

c 2017 The Author(s). Published by S. Karger AG, Basel www.karger.com/crg

Koizumi et al.: Utility of Glissonean Pedicle Transection for Surgical Treatment of Severe Liver Trauma

sive and involves the Glissonean pedicles near the hepatic hilus. We describe our 3 cases in detail and review our experience in light of the available literature.

(C) 2017 The Author(s)

Published by S. Karger AG, Basel

\section{Introduction}

In cases of severe liver trauma, damage control surgery (DCS) is commonly undertaken when the lethal triad is recognized [1,2]. Before the early 1980s, emphasis was placed on complete hemostasis and repair of all damaged organs. The concept of DCS is now widely accepted in Japan. DCS refers to a specific strategy: emergency exploratory laparotomy is undertaken for life-saving abdominal packing, especially liver packing; the patient is then monitored in the intensive care unit (ICU) until the components of the lethal triad are reversed, and definitive surgery is performed thereafter. Severe liver trauma with initial hemodynamic instability is the classic indication for DCS. DCS in such cases usually means perihepatic gauze packing to control bleeding from any of the branches of the portal vein or hepatic vein and then complementary transcatheter arterial embolization (TAE) for any arterial bleeding that continues afterward. Despite the widespread application of this strategy, mortality attributed to severe liver trauma remains unsatisfactorily high. We have applied the Glissonean pedicle approach, either ligation during DCS or transection for the definitive surgery, in 3 cases of severe liver trauma. We describe its application in detail and the case outcomes.

\section{Case Presentations}

Case 1

The patient was a 48-year-old man who was injured in an automobile accident in September 2011. He was transported to our hospital by emergency vehicle, and upon arrival, he was in shock and unresponsive. Focused assessment with sonography for trauma (FAST) revealed echo-free space in Morrison's pouch, and X-ray examination revealed displaced right lower fractures of ribs 5, 6, and 7 and hemopneumothorax. We attributed the shock to massive intra-abdominal hemorrhage resulting from internal organ damage and promptly initiated exploratory abdominal surgery. Time between the patient's arrival and the start of surgery was $55 \mathrm{~min}$. A midline incision was made, and massive bleeding was observed in the abdominal cavity (Fig. 1a). Because damage to the liver was confirmed at several points by palpation, the Pringle maneuver was immediately performed to interrupt the hepatic inflow. When the field was cleared of blood, we were able to see IIIb damage (Japanese Association for the Surgery of Trauma classification) at 3 sites in the right lobe (Fig. 1b-d). For damage at the 2 superior sites, branches of the right hepatic vein were exposed, and hepatorrhaphy was performed to control the bleeding. Damage at the inferior site was complicated because it involved the hepatic hilus, so a decision was made to perform perihepatic gauze packing without yet attempting to repair the damaged tissue. However, when the hemostat was released, bleeding from the hilar area was no longer controllable - the gauze packing alone was not sufficient. At this time, the anesthesiologist recognized the lethal triad and alerted us. With the critical need for complete hemostasis, ligation of the right Glissonean pedicles was decided upon. We first resected the gallbladder, and we dissected and encircled the anterior and posterior Glissonean pedicles individually at the secondary ramification, i.e. the 


\section{Case Reports in Gastroenterology}

Case Rep Gastroenterol 2017;11:190-200 DOI: $10.1159 / 000468514$

C 2017 The Author(s). Published by S. Karger AG, Basel www.karger.com/crg

Koizumi et al.: Utility of Glissonean Pedicle Transection for Surgical Treatment of Severe Liver Trauma

base of the anterior branch and posterior branch, and we taped them individually. By temporarily blocking the 2 branches, we achieved hemostasis, and there was no change in the color of the left lobe. Therefore, only double ligation of the Glissonean pedicles and simple perihepatic gauze packing were performed under the assumption that timely, definitive surgery would be performed. The total intraoperative blood loss volume was approximately $9,800 \mathrm{~mL}$, and the total DCS time was $94 \mathrm{~min}$. Abdominal computed tomography (CT) performed before the patient was admitted to the ICU depicted complete interruption of blood flow in the right hepatic lobe (Fig. 2). The patient revived, and we chose to observe him in the ICU for another $24 \mathrm{~h}$ in anticipation of definitive surgery.

Liver necrosis was suspected on the basis of laboratory tests performed serially (Fig. 3): by $21 \mathrm{~h}$ after the DCS, the aspartate aminotransferase (AST) and alanine aminotransferase (ALT) concentrations had gradually increased to 4,472 and 1,964 IU/L, respectively, and prothrombin time (as a percentage of normal, PT\%) rose to 95\% but fell to $63 \%$. By appearance, the liver was clearly necrotic, and for this reason the right hepatic vein was ligated before transection of the liver parenchyma (Fig. 4a), which was achieved by the clampcrushing technique (Fig. 4b). The Glissonean pedicles (anterior and posterior branches), which had been ligated during the initial operation, were transected (Fig. 4c). A photograph of the completed right hepatectomy is shown in Figure $4 \mathrm{~d}$, and the resected specimen is shown in Figure 5. The clinical course after the definitive operation was uneventful, and the patient was discharged 30 days after the DCS.

Case 2

The patient was a 42-year-old man who was injured in a motorcycle accident in October 2012. He was transported to our hospital by the emergency vehicle, and at the time of admission, he was hemodynamically stable. CT was performed, but during the secondary survey, he fell into a state of shock. He was immediately resuscitated, and emergency surgery was initiated. Time between the patient's arrival and the start of surgery was approximately $80 \mathrm{~min}$. When the midline incision was made, massive bleeding was observed in the abdominal cavity. Because the CT examination had revealed a large IIIb type injury of the right hepatic lobe involving the hilar area (Fig. 6), the Pringle maneuver was performed promptly to interrupt the hepatic inflow. Exploration of the abdominal cavity revealed damage to a branch of the superior mesenteric vein (SMV). After the SMV was repaired, the hilar area was easily examined in detail. A large laceration was apparent near the base of the posterior Glissonean pedicle (Fig. 7a). This meant that repairing the right hepatic lobe would be difficult, so we performed Glissonean pedicle ligation as a means of damage control. As in case 1, after having resected the gallbladder, we dissected the right anterior and posterior Glissonean pedicles and ligated them individually. The total intraoperative blood loss volume was approximately $11,500 \mathrm{~mL}$, and the total operation time was $85 \mathrm{~min}$. According to our experience in case 1 , we performed definitive systematic right hepatectomy in a timely manner to ward off liver necrosis. The surgical specimen is shown in Figure $6 \mathrm{~b}$. The postoperative clinical course was good, allowing for orthopedic surgery to be performed 10 days later. The patient was discharged 31 days after the DCS.

\section{Case 3}

The patient was a 24-year-old man who was injured in a motorcycle accident in November 2016. He was in a state of shock at the time of emergency conveyance, and although his blood pressure (BP) was restored with resuscitative infusion of physical saline, hypotension ensued. FAST revealed echo-free space in Morrison's pouch. CT performed after tracheal 


\section{Case Reports in Gastroenterology}

Case Rep Gastroenterol 2017;11:190-200 DOI: 10.1159/000468514

(c) 2017 The Author(s). Published by S. Karger AG, Basel www.karger.com/crg

Koizumi et al.: Utility of Glissonean Pedicle Transection for Surgical Treatment of Severe Liver Trauma

intubation revealed damage to and collapse of most of the right hepatic lobe, with active extravasation seen in the arterial phase (Fig. 8a). Because the patient's BP decreased again during the CT examination, TAE was performed immediately. The time from the patient's arrival to this damage control intervention was approximately $40 \mathrm{~min}$. TAE was performed until the extravasation disappeared (Fig. 8b); the BP stabilized. The patient was then admitted to the ICU. Because coagulopathy (PT\% 1 day after TAE was 48\%) and acute hepatic necrosis occurred (AST and ALT 1 day after TAE were 5,518 and 3,355 IU/L, respectively) (Fig. 3), and signs of abdominal compartment syndrome (increased intravesical pressure and exacerbation of renal function), CT was performed (Fig. 8c), and systematic right hepatectomy as definitive surgery was initiated $24 \mathrm{~h}$ after the TAE on the basis of the CT findings of extensive right lobe necrosis. When the midline incision was made, massive bleeding and clots were observed in the abdominal cavity. After sweeping the cavity clean of the blood and clots, we performed the Pringle maneuver, and 4 large and complicated right hepatic lobe lacerations were seen. Necrotic changes with a very unpleasant odor were also found (Fig. 9a). After routine cholecystectomy, right hepatectomy was performed by the Glissonean pedicle transection method (Fig. 9b). This surgery went more smoothly than the surgeries in cases 1 and 2 because the patient's hemodynamics remained stable. The total intraoperative blood loss was approximately $5,817 \mathrm{~mL}$, and the total operation time was 277 min. The time for hepatectomy alone was about $120 \mathrm{~min}$. No major problems ensued, and the patient was discharged 30 days after the surgery.

All 3 patients remain well. There have been no serious postoperative complications, and all have been able to resume their normal activities.

\section{Discussion}

Trauma is injury to an organ caused by an external force. Three very important possible consequences are massive bleeding, inflammation, and infection. Thus, the basic principle underlying trauma treatment is 3-fold: (1) control of the bleeding, (2) control of the inflammation and infection, and (3) maintenance or restoration of the function of the damaged organ [3]. These principles are applicable to liver injury, and of primary importance in cases of liver injury with hemodynamic instability is control of the bleeding. The Pringle maneuver [4] is the most widely recognized technique for control of bleeding resulting from liver trauma. However, this maneuver can be applied only temporarily - in the range of 15-45 min. Therefore, it is incumbent upon surgeons to complete the organ repair during this limited timeframe. If the damaged portion of the liver is small and uncomplicated, existing techniques such as hepatorrhaphy and/or omental packing are applicable. In cases of extensive or severe damage, perihepatic gauze packing and complementary TAE [5] are generally performed. However, this strategy raises the following questions: Is it really possible to achieve complete hemostasis by means of complementary TAE in the face of coagulopathy? Can the bleeding from hepatic or portal veins be stopped simply by perihepatic gauze packing? Does postoperative biliary fistula occur if the injury involved the Glissonean pedicles in the hilar area? These are critical questions, pointing to the importance of reliable hemostasis and systematic anatomical hepatectomy that includes the damaged areas. Performing major hepatectomy initially in the face of the lethal triad would be reckless. For this reason, limited resectional debridement is generally performed in cases of severe liver trauma. The 3 cases we present here suggest a new strategy to overcome the weak points of previous strategies. Ligation of Glissonean pedicles included in the damaged area will prevent uncertain hemo- 


\section{Case Reports in Gastroenterology}

Case Rep Gastroenterol 2017;11:190-200 DOI: 10.1159/000468514

c 2017 The Author(s). Published by S. Karger AG, Basel www.karger.com/crg

Koizumi et al.: Utility of Glissonean Pedicle Transection for Surgical Treatment of Severe Liver Trauma

stasis, and dividing treatment into 2 stages (damage control treatment and definitive treatment) will allow for timely, appropriate management of the critical clinical situation. If we know in advance that the main bleeding source is an artery in the damaged part of the liver, TAE is an option for damage control, as in our case 3.

The Glissonean pedicle ligation method is a modification of the Takasaki Glissonean pedicle transection method [6]. Takasaki devised this method for safer and quicker performance of hepatectomy in patients with liver cancer. His idea was as follows. The Glissonean pedicle contains 3 vessels: the portal vein, hepatic artery, and bile duct. In terms of the Glissonean pedicle tree, the liver can be divided into 3 segments, and the corresponding Glissonean pedicles (branches within the anterior sector, posterior sector, and left liver) can be encircled and taped individually extrahepatically. The procedure is not only easy, but it is quite advantageous because if we treat the Glissonean pedicle on the basis of this concept, biliary damage is unlikely to occur as a postoperative complication. That is why the Takasaki method is now considered a basic manual skill by liver surgeons in Japan.

It is conceivable that the Takasaki method is suitable for surgery in cases of liver trauma from the standpoint of improving safety and shortening the operation time. The Takasaki method is useful as a damage control technique in cases of a large complicated liver injury involving the hilus because permanent inflow occlusion is possible on the premise of resection. The procedure can be accomplished safely in a short time even during definitive surgery, provided the patient is hemodynamically stable. We applied the Takasaki concept as Glissonean ligation during DCS in cases 1 and 2 and as Glissonean transection for definitive treatment after TAE in case 3 because we were already very comfortable with it. The technique may be useful, but it should be restricted to certain kinds of cases. First, the strategy should be limited to cases in which damage involves the Glissonean pedicles near the hepatic hilus and bleeding would be hard to control by other maneuvers generally practiced in cases of liver trauma. It is not effective in cases of juxta hepatic venous injury. Second, it is very important that the hepatic functional reserve be accurately evaluated. In the trauma scenario, unlike the planned surgery scenario, the evaluation must be done on the basis of the appearance and feel of the liver, and this requires experience. Third, because necrosis will occur rapidly in the segment fed by the ligated Glissonean pedicle, definitive surgery should be performed as soon as possible after the ligation. If anatomical systematic hepatectomy cannot be performed within $24 \mathrm{~h}$, Glissonean pedicle ligation should not be performed during DCS. This point also applies to cases in which TAE is being considered instead of Glissonean pedicle ligation because necrosis will develop rapidly in the embolized area when the liver damage is severe.

The appropriate timing for the definitive surgery remains to be established. The postDCS changes in the AST and ALT levels over time in our cases 1 and 3 were similar. The levels increased dramatically starting approximately $14 \mathrm{~h}$ after the DCS. PT\% too worsened similarly over time, with a peak within $10 \mathrm{~h}$ after DCS and then a sharp decrease after $14 \mathrm{~h}$. This pattern is thought to be due to the acute liver infarction. According to our experience, it seems that 8-12 $\mathrm{h}$ after DCS is appropriate for performing the definitive surgery, given that the liver has not yet succumbed to extensive infarction and the coagulatory function has recovered optimally.

We devised this Glissonean pedicle ligation strategy in September 2011, and we reported it in 2013 [7]. To date, we have applied it in only 3 cases. Widespread adoption of this new strategy will be gradual. Although Glissonean pedicle transection is quite familiar to liver surgeons in Japan, it is not familiar to trauma surgeons. In addition, unlike the Pringle maneuver, which is easily learned, the Glissonean pedicle ligation/transection cannot be 
Koizumi et al.: Utility of Glissonean Pedicle Transection for Surgical Treatment of Severe Liver Trauma

learned without much practice. The ligation or transection can be completed in a few minutes by a liver surgeon who is used to it, but when performed by an inexperienced surgeon, the procedure not only takes a long time, but can also increase the area of injury.

\section{Conclusion}

We expect the Glissonean pedicle ligation approach to prove advantageous in DCS in cases of severe liver trauma with hemodynamic instability. We also expect Glissonean pedicle transection to prove advantageous for definitive surgery after damage control by TAE. Acquisition of the necessary skill may be time consuming, but the time invested will become exceptionally rewarding when liver damage involves the hepatic hilus and Glissonean pedicles.

\section{Statement of Ethics}

We obtained the patients' written informed consent to publish this case series and the publication has been approved by our institute's Committee on Human Research.

\section{Disclosure Statement}

The authors declare no conflict of interest. There was no grant support.

\section{References}

1 Rotondo MF, Schwab CW, Mc Gonigal MD: "Damage control”: an approach for improved survival in exsanguinating penetrating abdominal injury. J Trauma 1993:35:375-382; discussion 382-383.

2 Eddy VA, Morris JA Jr, Cullinane DC: Hypothermia, coagulopathy, and acidosis. Surg Clin North Am 2000;80:845-854.

3 Koizumi S, Kobayashi S, Negishi H, Miura K, Katayama M, Matsumoto J, Taira Y, Otsubo T: Strategies for treating traumatic injury to the pancreas and duodenum at a single hospital. J Abdom Emerg Med 2012;32:1151-1156.

4 Pringle JH: Notes on the arrest of hepatic hemorrhage due to trauma. Ann Surg 1908;48:541-549.

-5 Kozar RA, Feliciano DV, Moore EE, Moore FA, Cocanour CS, West MA, Davis JW, McIntire RC Jr: Western Trauma Association/critical decisions in trauma: nonoperative management of adult blunt hepatic trauma. J Trauma 2009;67:1144-1148; discussion 1148-1149.

-6 Takasaki K: Glissonean pedicle transection method for hepatic resection: a new concept of liver segmentation. J Hepatobiliary Pancreat Surg 1998;5:286-291.

7 Koizumi S, Saji O, Katayama M, Kishi S, Kobayashi S, Nakano H, Taira Y, Otsubo T: Glissonean pedicle ligation method as the optional technique of damage control surgery for severe liver trauma. Jpn J Acute Care Surg 2013;3:61-69. 


\section{Case Reports in Gastroenterology}
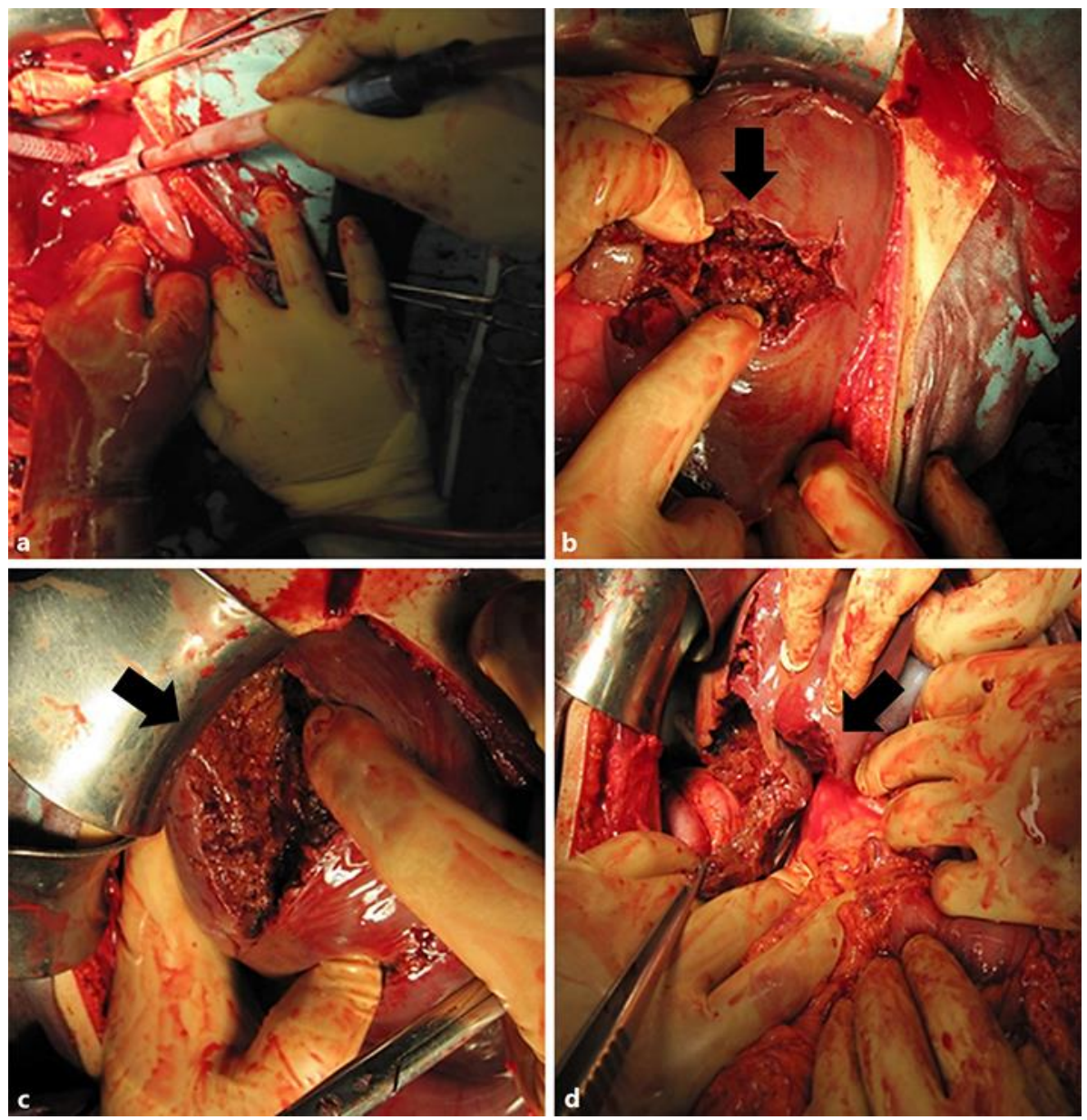

Fig. 1. Intraoperative photographs - case 1. a Upon incision at the abdominal midline, massive bleeding was seen in the abdominal cavity. The patient was positioned with his head to the right. IIIb damage to the right hepatic lobe was discovered at 3 sites (arrowheads): at the superior portion (b), on the surface (c), and at the inferior border (d). If included, the patient's head would be at the top of the photograph. 


\section{Case Reports in Gastroenterology}
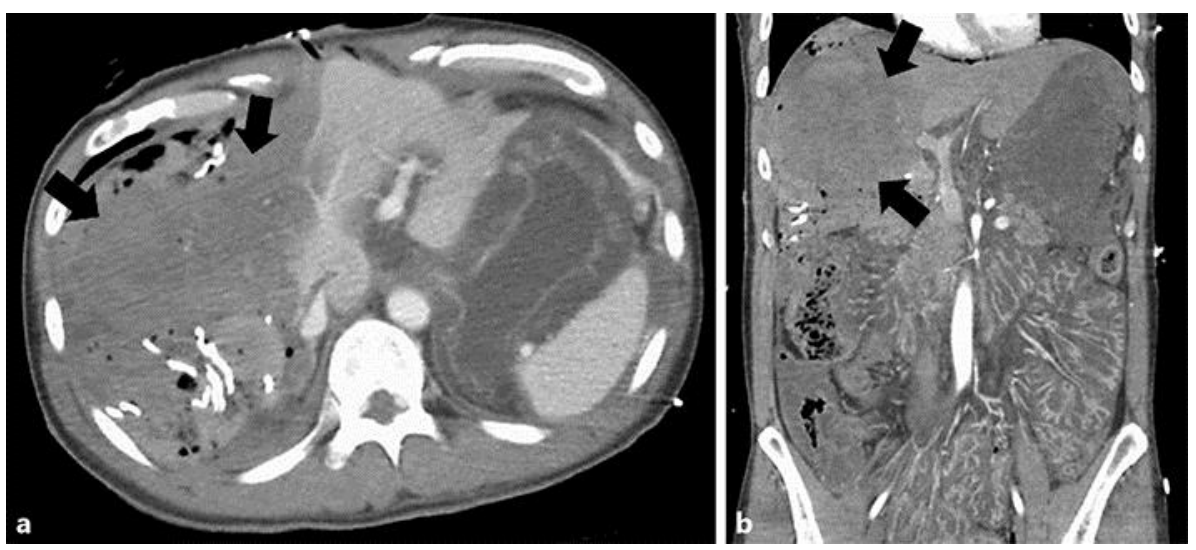

Fig. 2. CT images obtained just after Glissonean pedicle ligation was performed as damage control surgery - case 1. Abdominal CT performed after Glissonean pedicle ligation revealed fully interrupted blood flow in the right hepatic lobe. a Axial image shows absence of blood (arrowhead) in the right lobe, which has been packed with gauze. b Multiplanar reconstruction image more clearly depicts absence of blood (arrowhead) in the right hepatic lobe.

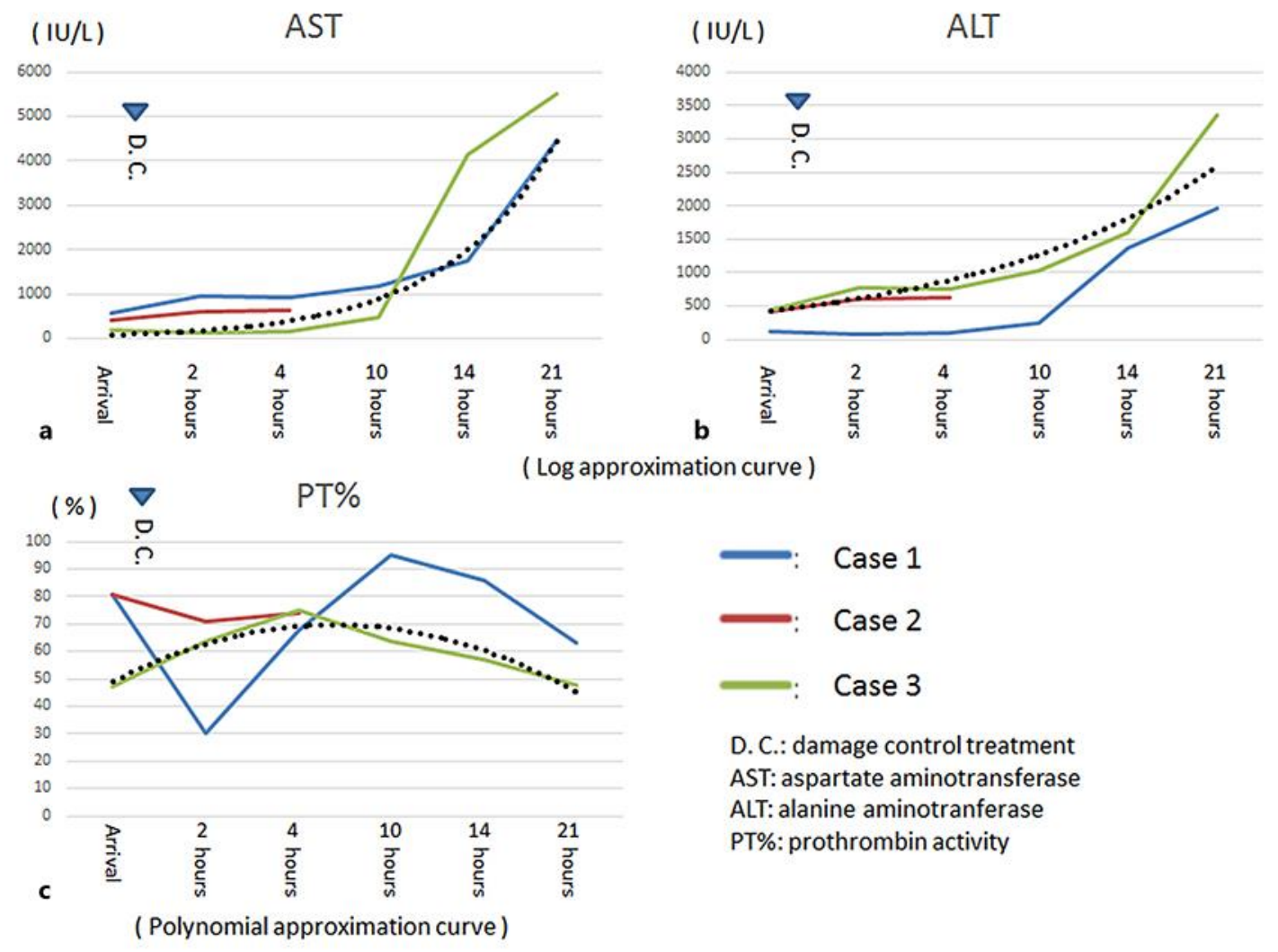

Fig. 3. Changes in AST, ALT, and PT\% over time in the 3 patients. a, b Black dashed lines are log approximation curves. c Black dashed line is a polynomial approximation curve. 


\section{Case Reports in Gastroenterology}

\begin{tabular}{l|l}
\hline Case Rep Gastroenterol 2017;11:190-200 \\
\hline DOI: 10.1159/000468514 & $\begin{array}{l}\text { ○ 2017 The Author(s). Published by S. Karger AG, Basel } \\
\text { www.karger.com/crg }\end{array}$ \\
\hline
\end{tabular}
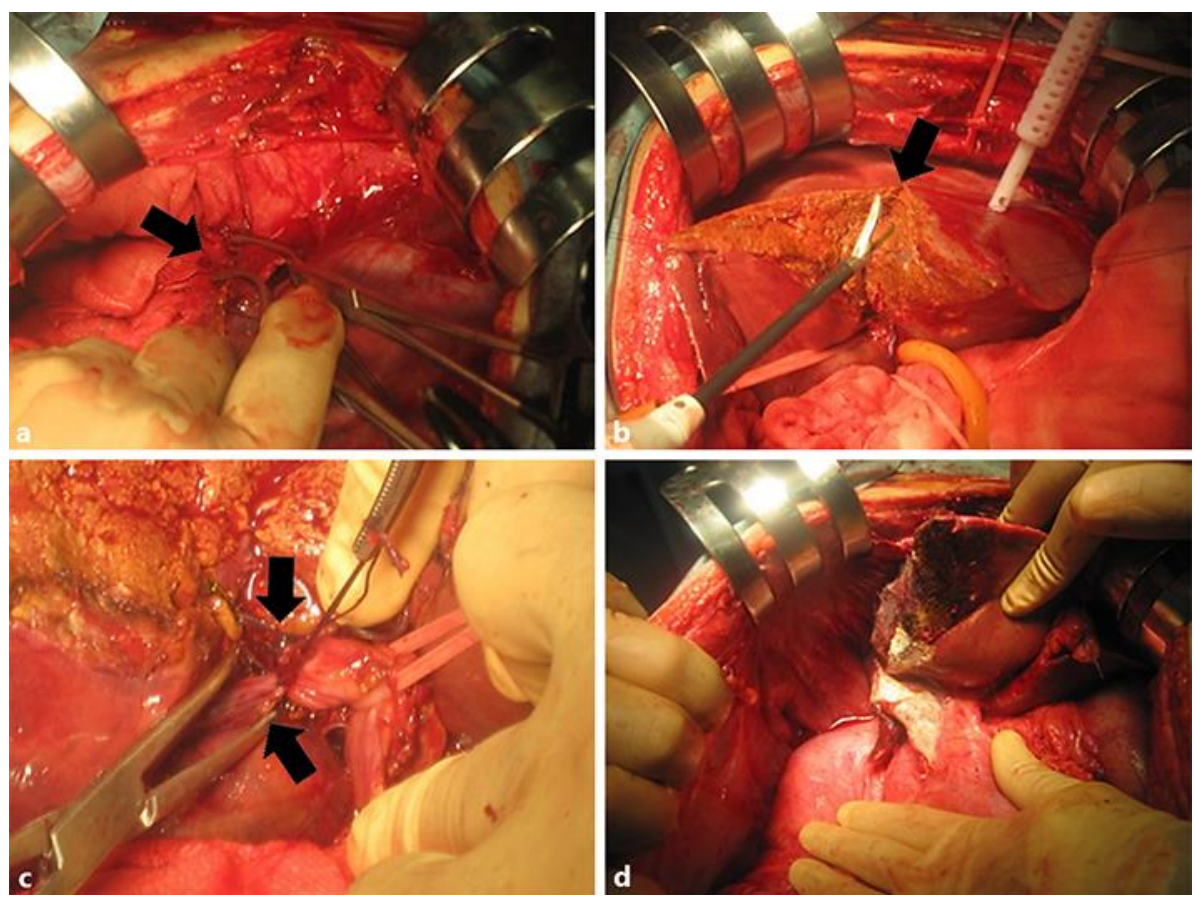

Fig. 4. Intraoperative photographs of the definitive surgery - case 1. a The right hepatic vein (arrowhead) was ligated before transection of the liver parenchyma. $\mathbf{b}$ The liver parenchyma (arrowhead) was transected by the clamp-crushing method. c The Glissonean pedicles (anterior branch and posterior branch, [arrowheads]) were transected distal to the point of ligation. $\mathbf{d}$ Appearance of the liver upon completion of the right hepatectomy.



Fig. 5. Resected right hepatic lobe - case 1. Photograph obtained shortly after the surgery. The right side of the specimen is the cut side. Large lacerations (arrowheads) are visible at multiple sites. 


\section{Case Reports in Gastroenterology}

Case Rep Gastroenterol 2017;11:190-200

DOI: $10.1159 / 000468514$

(c) 2017 The Author(s). Published by S. Karger AG, Basel www.karger.com/crg

Koizumi et al.: Utility of Glissonean Pedicle Transection for Surgical Treatment of Severe
Liver Trauma

Koizumi et al.: Utility of Glissonean Pedicle Transection for Surgical Treatment of Severe
Liver Trauma
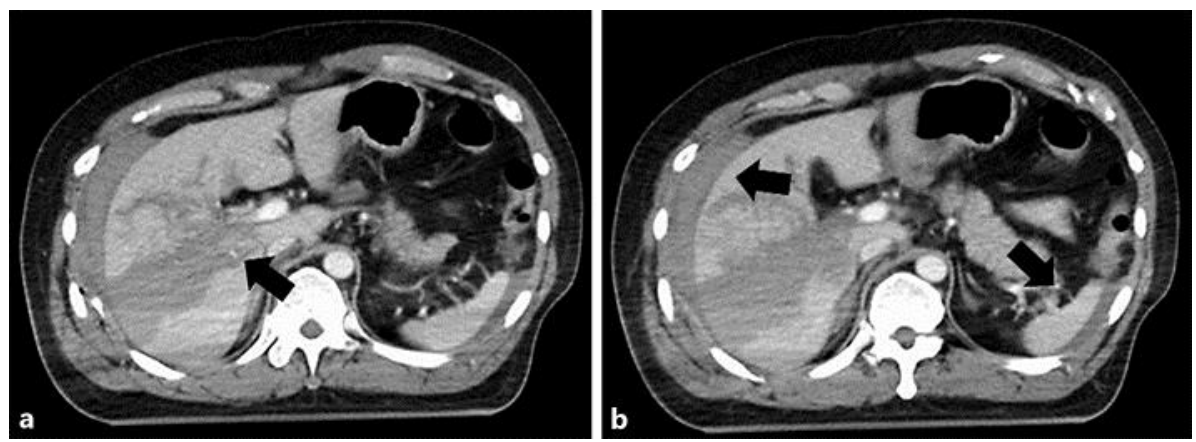

Fig. 6. CT images obtained at the start of the secondary survey - case 2. a A large IIIb type right hepatic lobe injury (arrowheads) that involved the hilar area was revealed. b A large volume of blood (arrowheads) was detected around the liver and spleen.
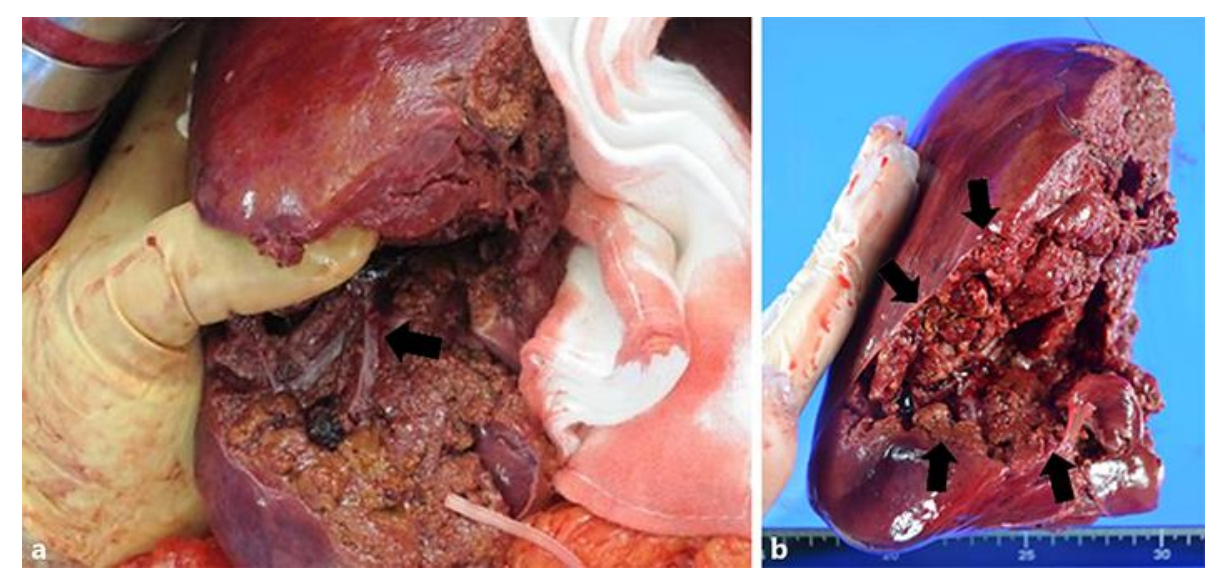

Fig. 7. Photographs obtained during and after the surgery - case 2. a The right hepatic veins (arrowheads) were exposed in the laceration. b Resected right hepatic lobe. Large lacerations (arrowheads) involving the hepatic hilus are apparent. 


\section{Case Reports in Gastroenterology}
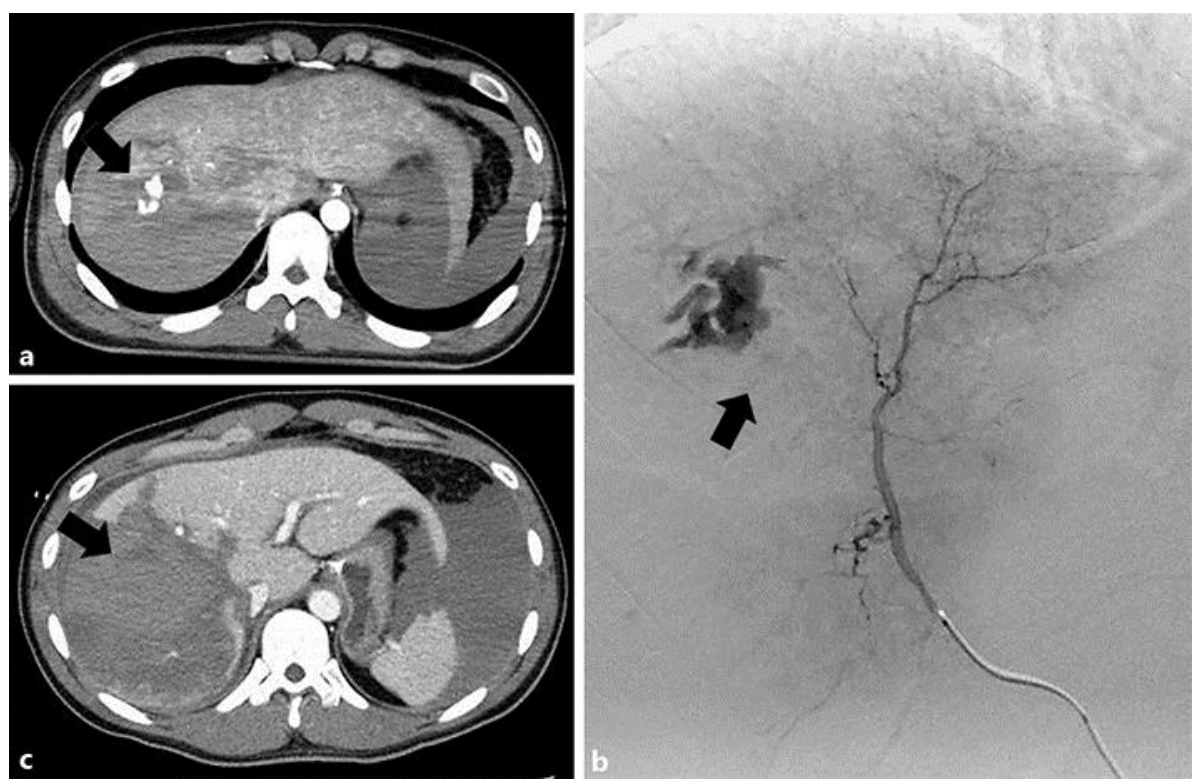

Fig. 8. CT and angiographic images - case 3. a Most of the right hepatic lobe appeared collapsed and thus severely damaged, and extravasation (arrowheads) was seen in the arterial phase in the same area. A large volume of blood (arrowheads) was also seen around the liver and left subphrenic recesses. b Upon angiography, extravasation was seen mainly in the area of the right hepatic artery (arrowhead). TAE was performed until the extravasation disappeared. c CT image obtained 1 day after TAE. Most of the right hepatic lobe had fallen into hemorrhagic necrosis (arrowheads).
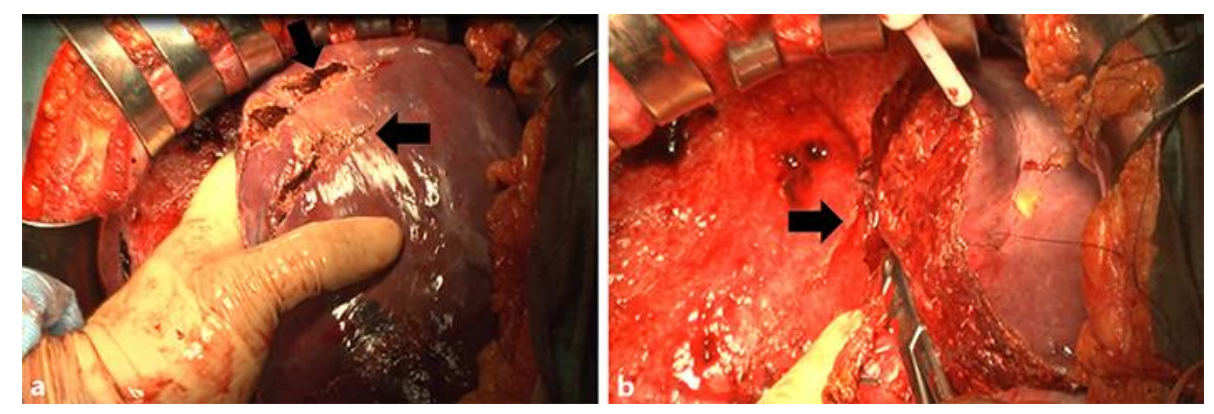

Fig. 9. Intraoperative photographs - case 3. a Four large, complicated lacerations and necrotic changes (arrows) were found in the right hepatic lobe. b Upon completion of the right hepatectomy, forceps were used to grasp the stump of the right hepatic vein (arrowhead). 